\title{
Activity Based Aggregate Job Costing Model for Reconfigurable Manufacturing Systems
}

\author{
Darwish Alami ${ }^{1}$ and Waguih ElMaraghy ${ }^{1, *}$ \\ 1 Industrial and Manufacturing Systems Engineering, University of Windsor, \\ 401 Sunset Ave. Windsor, Ontario N9B 3P4, Canada \\ * Corresponding author: wem@uwindsor.ca
}

\begin{abstract}
Manufacturing continues to face escalated cost challenges as the global economy grows. In order to gain competitive advantage among its rivals, manufacturing firms are in a constant strive to lower their manufacturing costs compared to their competitors. This paper introduces a mathematical optimization model based on Activity Based Costing (ABC) method for Reconfigurable Manufacturing Systems (RMS) taking into consideration the bi- directional relationship between hourly rates and annual hours on each machine/workcentre. The output from the model will be the optimum hourly rates, decision on which jobs to accept or reject and decision on the financial feasibility of reconfiguration. Reconfiguration in this paper describes both system-level reconfiguration (investing in additional machining equipment) and/or, machine-level reconfiguration (extra module to an existing equipment). The model will be applied on a real life case study of a global Original Equipment Manufacturer of Machinery. The novelty of the proposed model is the incorporation of the bi-directional relationship between hourly rates and annual hours on each machine and provides a managerial decision making tool in terms of investment level required to pursue new business, and gaining competitive advantage over rivals.
\end{abstract}

Key words: Activity Based Costing, Reconfigurable Manufacturing Systems, Direct cost

\section{1- Introduction}

Manufacturing firms are striving nowadays to deliver a portfolio of products to its customers with attainable prices to increase the market share of their products. Since the product development process includes various numbers of interconnected activities, it is of a great challenge to manufacturing firms to trace and allocate the different activities to cost objects in order to specify the price of their products and services.

Cost accounting is the type of cost incurred after the product is manufactured. This type of cost is prepared by accountants. There are several types of cost accounting. Process costing method is employed when a standard product is being made which involves a number of distinct processes performed in a definite sequence. Process costing is applied mainly in continuous manufacturing (i.e. oil refinery). It is applied to manufacturing environment in which similar products are produced. Job costing is concerned with finding the cost of each individual job or contract. Batch costing is a form of job costing. Instead of costing each component separately, each batch of components are taken together and treated as a job. 
Hybrid costing is a combination of the above.

In addition, there exist three main cost systems: (i) traditional costing system, (ii) Activity Based Costing (ABC) and (iii) variable based costing [1, 2]. Monroy el al. [3] presented the three different accounting systems' approaches to manufacturing; (i) Activity Based Costing, (ii) Time Driven Activity Based Costing and (iii) Lean Accounting.

As lean manufacturing implies identification of non-value added activities and reduce them (if not eliminating them), lean accounting can also be defined as removing or eliminating waste within the accounting process itself. There are three supporting key points for applying lean accounting in lean organization: visual management, value stream management and continuous improvement [4]. Throughput accounting cost includes direct materials and direct labor which is used in Just In Time manufacturing environment. Throughput is defined as the difference between revenue and the total variable expenses as per [5]. The main difference between the traditional accounting and the throughput accounting costing is the bottleneck operation or drum. For the throughput accounting technique, it mandates optimizing the bottleneck operation only since any local optimization of non-bottleneck operations will result in buffer accumulation. Unlike the traditional accounting cost, which requires all firm operations to run as efficient as possible (as well as non-bottleneck operations [5] . It has been reported by [6] that the usage of throughput costing aided companies in reducing lead time, inventory and cycle time while increasing productivity and quality. More on product costing methods is shown in Fig. 1.

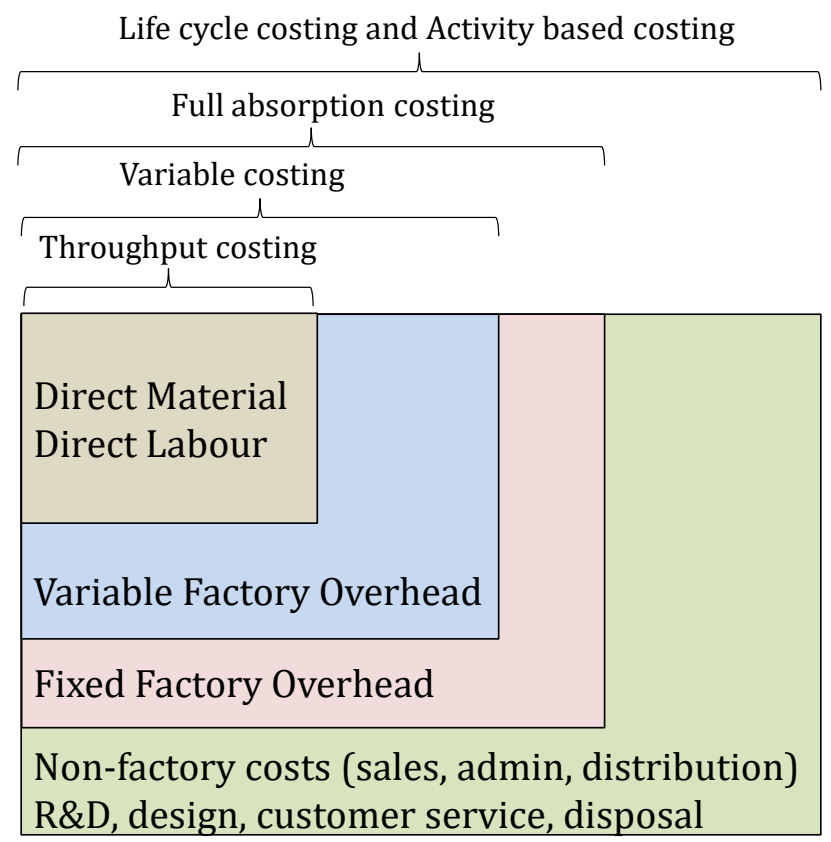

Fig. 1. The different types of product costing [7]

This paper introduces a novel mathematical model to minimize the total cost incurred in a job shop environment across production periods. The cost objects in this case refers to the jobs being processed within the manufacturer's floor (cost objects refers to an entity in which cost measurement is desired such as products, services, activities and customers [8]). The mathematical model takes into account the bi-directional relationship between hourly rates and the total assigned hours as well as reconfiguration decision within machine and system 
level. Hence, this paper deals with job costing type of cost accounting due to its relevance with job shop environment. In addition, the cost system used is ABC due to its accuracy in allocating overhead costs to cost objects. In addition, workcentres and engineering department capacities are taken into consideration as constraints. The mathematical model developed for this paper is non-linear and hence, in order to convert it to a Mixed Linear Integer Programming model, several linearization techniques will be applied.

This paper is organized as follows; section 2 is concerned with reviewing the previous work and identifying the gap, section 3 provides a background to two main elements in this paper which are the ABC method and manufacturing systems, section 4 is concerned with the mathematical model development, section 5 presents a case study for applying the mathematical model, section 6 lists the results and discussions from the case study and finally, section 7 is the conclusion.

\section{2- Literature Survey}

Lin et al. [9] provided a model for integrating manufacturing and production system performance cost. The integration between manufacturing and costing was achieved by linking the Activity Based Costing (ABC) and Design for Manufacturing (DFM). Ramadan et al. [10] proposed a real time manufacturing cost estimation method using RFID. It was concluded that the proposed real time manufacturing tracking system is beneficiary in identifying causes for redundant cost which can be an enabler for lean manufacturing. Myrelid and Olhager [11] proposed a hybrid cost approach for mixed process environment (job shop, flow shops and assembly lines) in order to establish a cost allocation for products produced by manufacturer. Traditional, lean and throughput accounting approaches were used and applied on three different products with varying complexity. Mathematical formulae were formulated for each approach. They concluded that lean accounting cost model is to be allocated to assembly lines, throughput accounting cost model to flow shops and traditional accounting cost to job shop environment. Elsukova [12] illustrated the lean and throughput cost accounting approach and proposed a framework for integrating both approaches. The author concluded that the lean and throughput cost accounting approaches supplement one another as the throughput cost accounting determines the improvement required for the flow of material (restricted by bottlenecks) and lean cost accounting is mandatory to improve production and reduce waste. Sajadfar and Ma [13] proposed a framework for cost estimation for welded features using data mining and linear regression to come up with a feature cost estimation. Jiang et al. [14] proposed a manufacturing cost model which takes into consideration labor, material and overhead costs for mycelium-based bio-composite sandwich structures. Duran and Afonso [15] proposed an Activity Based Costing and Life Cycle Costing (LCC) model as a decision making tool for management of non-repairable spare parts. Santana et al. [16] proposed a mathematical model incorporating Activity Based Costing and Time Based Activity Based Costing for capacity management optimization. The trade-off between capacity maximization and operational efficiency has been analyzed and the authors suggested that capacity should be optimized rather than maximized since maximizing capacity can lead to operational inefficiency. Tsai et al. [17] proposed a Green Activity Based Costing (ABC) model applied within aluminum alloy wheel industry. The 
model traces direct and indirect product costs to cost objects as well as allocates carbon tax to cost objects. Tsai and Lai [18] proposed a mathematical programming model combining green manufacturing technologies (i.e.), Activity Based Costing (ABC) and theory of constraint in order to provide optimal production plans based on optimal profitable product mix decision. The labour rates in the model have been considered as an input parameter to the model and the bi-directional effect between labour rate and hours assigned to workcentres was not considered.

From the conducted literature review, the bi-directional between direct hourly rates and total hours assigned to departments/workcentres has not been discussed before. In addition, this paper incorporates the machine/module reconfiguration cost, depending on financial feasibility, if they will increase assigned hours in facility and hence reducing the hourly rates.

\section{3- Activity Based Costing}

The activity based costing, originally introduced by [19, 20], works differently from the traditional costing system. The main benefits of the ABC costing is the allocation of unit cost of a product based on the capacity used for product or job. It starts by defining the different activities involved in production (e.g. setup, machining....etc.), compute the cost for each activity and then allocate each activity to its corresponding cost objects such as product or job. This type of system works well for companies producing a wide scope of product variants or jobs. The steps for $\mathrm{ABC}$ can be shown in Fig. 2. The main drawback of the $A B C$ method is its complexity in identifying the various activities which is time consuming and requires high data processing costs.

For the ABC method, the hourly rate in specific period for a certain workcentre or engineering activity is proposed as:

$$
\begin{aligned}
& \text { Hourly rate for certain machine or activity in period }(t)= \\
& =\text { Blended cost }+\frac{\text { General assets allocated } \operatorname{cost}_{A B C}+\text { Depreciation } / y r}{\text { total hours by machine or activity in period }(t-1)}
\end{aligned}
$$

In Equation (1), the "General assets allocated cost $A B C$ " is the portion of the general assets allocated to a certain workcentre or activity. It is defined as the product of the total general assets in a specific production period and the ratio between the hours assigned to a workcentre/activity to the total hours by all workcentres/activities. As per Equation (1), it is evident that hourly rate in a certain production period decrease as the total hours by machine or activity increase in the previous production period. 


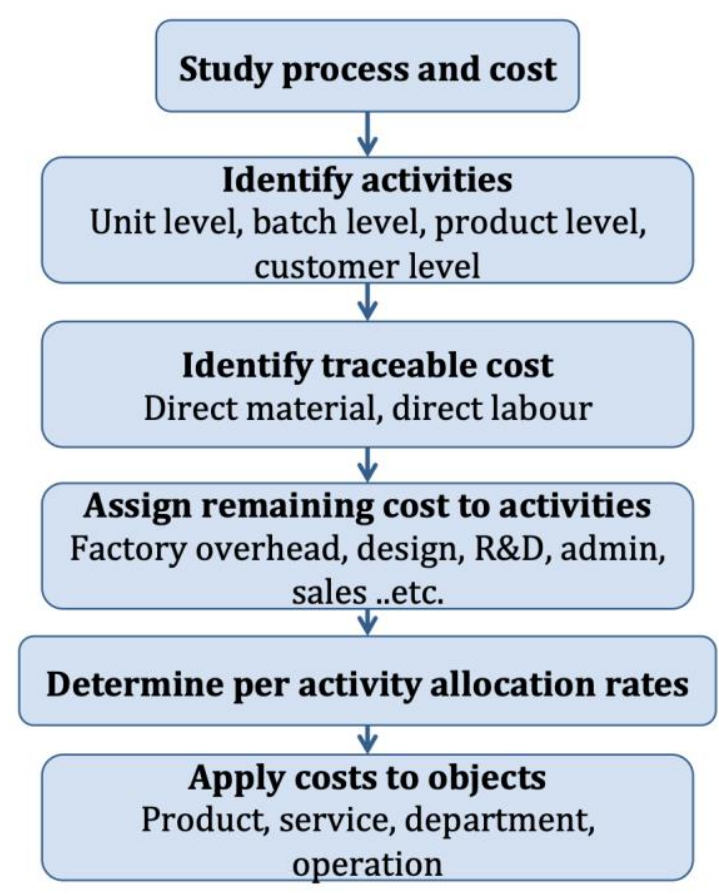

Fig. 2. Activity Based Costing steps

\section{4- Manufacturing Systems}

Manufacturing systems have evolved along decades depending on customers' requirement and needs in each era and through each industrial revolution. In industry 1.0, steam power was the main enabler for industry 1.0 in an attempt to fulfil production volume to the market. The production system type during industry 1.0 was called a craft production system. With the introduction of electricity and mechanical devices, industry 2.0 took over in which dedicated manufacturing lines were capable of satisfying production volume and variety. Afterwards, with the advancements in micro processing and computers, industry 3.0 evolved with Flexible Manufacturing Systems as its main essence with focus on production volume, variety and delivery time. Industry 4.0 is the new industrial revolution enabled by the breakthrough in Information and Communication Technology (ICT), Internet of Things (IoT), Cloud Computing and Cyber-Physical Systems [21]. Reconfigurable Manufacturing Systems and Distributed Manufacturing Systems are the main production systems type in Industry 4.0.

Dedicated manufacturing lines (DML), or transfer lines [22], are based on inexpensive fixed automation and produce a company's core products or parts at high volume. Each dedicated line is typically designed to produce a single part (i.e., the line is rigid) at high production rate achieved by the operation of several tools simultaneously in machining stations (called "gang drilling"). When the product demand is high, the cost per part is relatively low. DMLs are cost effective as long as demand exceeds supply and they can operate at their full capacity. But with increasing pressure from global competition and overcapacity built worldwide, there may be situations in which dedicated lines do not operate at full capacity. Flexible manufacturing systems (FMS)[22, 23] can produce a variety of products, with changeable volume and mix, on the same system. FMSs consist of expensive, 
general-purpose computer numerically controlled (CNC) machines and other programmable automation. Because of the single-tool operation of the CNC machines, the FMS throughput is lower than that of DML. The cost per part relatively high due to the high cost of the general purpose machine and low throughput. Reconfigurable Manufacturing Systems is type of system characterized by rapid adjustability of functionality and capacity to meet changing demand $[23,24]$. The design of the reconfigurable manufacturing systems is intended for part family, unlike DML and FMS which mainly focus on single part and general purpose machine, respectively. There are several characteristics and enablers that qualify a system as reconfigurable. These characteristics are [24]:

Modularity: modular system components to facilitate adjustment of the system capacity and capability (adding/removing system components).

Integrability: all system components must be easily integrated through appropriate interfaces.

Convertibility: quick changeover when changing between products (mixed model production)

Diagnosability: quick identification of errors or malfunctions

Customization: match system capability and capacity to the product demand

Scalability: incremental increase or decrease in system capacity by adding or removing system components easily.

Focused Flexibility Manufacturing Systems [25] is a hybrid type of manufacturing systems in which Flexible Manufacturing Systems (FMS) exist with Dedicated Manufacturing Lines and hence, flexibility is introduced not only through the individual general purpose machines (e.g. CNC), but from the interaction between the two systems. Job Shop [26] consists of a group of general purpose machines (e.g. CNC) together with often dedicated equipment to mainly suit low volume production with high variety. Normally, there is no specific type of flow in job shops due to its nature as a make-to-order type of facility which depends on the customer's orders (daily orders can vary from full size presses to small size spare parts). This leads to complex scheduling and material handling within the shop. Cellular Manufacturing Systems [27] is based on grouping of part families which are similar in shape, material and manufacturing process and assign them to a group of machines known as cells. A key enabler of cellular manufacturing is group technology. Group technology is a concept in which relies on grouping parts sharing similar design, material and manufacturing process into part families.

\section{5- Mathematical Model Formulation}

This section lists and illustrates the mathematical model implemented in this paper. The IDEF0 model is shown in Fig. 3. The detailed description of the model, inputs and outputs will be illustrated in the following subsections. The proposed model is non-linear. In order to obtain the linear form and convert it to a Mixed Integer Linear Programming (MILP) model, reader can refer to linearization methods in [28]. 


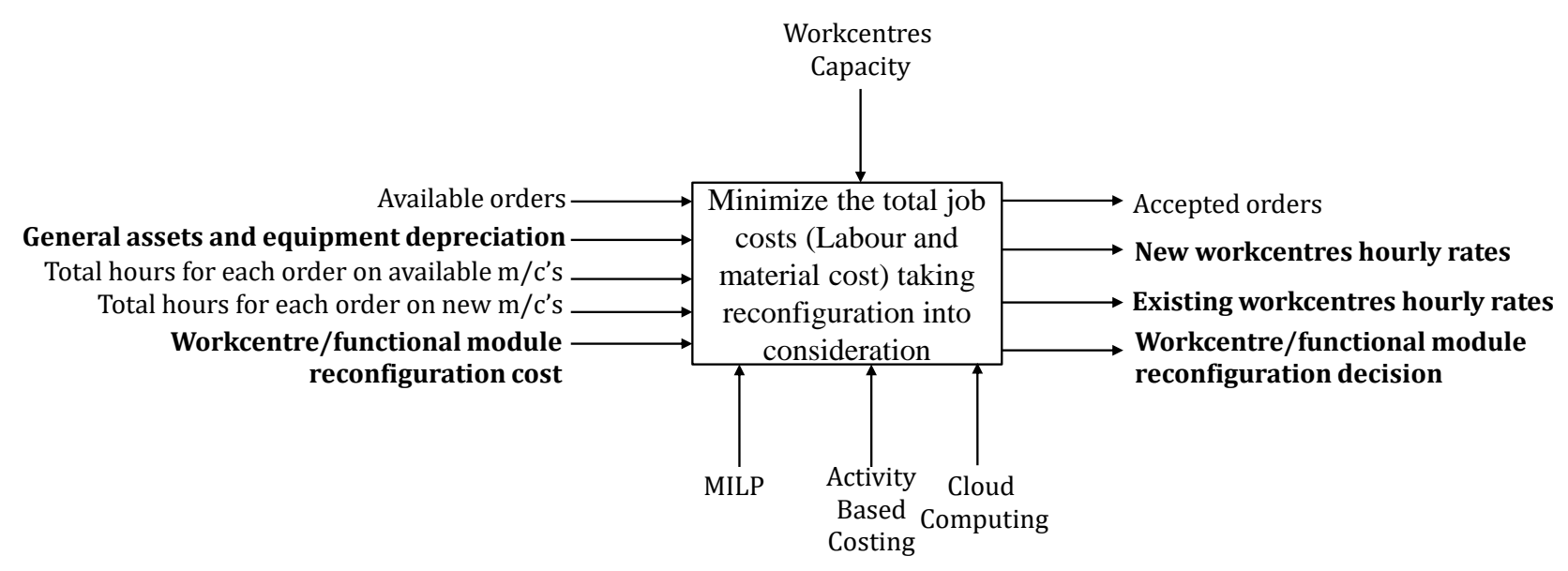

Fig. 3. IDEF0 model for the proposed mathematical model

The list of input parameters, decision variables, sets, constants objective function, constraints are detailed in this section. The list of input parameters is:

$e_{i, o}=\left\{\begin{array}{l}1, \text { if workcentre } o \text { can operate on job } i \\ 0, \text { otherwise }\end{array}\right.$

$f_{m, i, o}:$ Quoted/budget hours required for workcentre $o$ to complete job $i$ when module $m$ is added

$g_{i, o}$ : Quoted/budget hours required for workcentre $o$ to complete job $i$

$g_{i, p}^{N E W}:$ Quoted/budget hours required for workcentre $p$ to complete job $i$

$h_{i, j}$ : Quoted/budget hours required for engineering dept. $j$ to complete job $i$

$k_{i, o}$ : Quoted/budget hours required to setup workcentre $o$ for job $i$

$k_{i, p}^{N E W}:$ Quoted/budget hours required to setup workcentre $p$ for job $i$

$Q_{i, t}:$ Production demand/quantity of job $i$ in production period $t$

$d_{i, t}$ : Raw material/commercial items cost for job $i$ in production period $t$

$s_{i, t}$ : Selling price of job $i$ in production period $t$

$C_{o, t}^{M}$ : Available capacity for workcentre $o$ in production period $t$

$C_{p, t}^{M N E W}$ : Available capacity for workcentre $p$ in production period $t$

$C_{j, t}^{E}$ : Available capacity for engineering department $j$ in production period $t$

$D E P_{o}^{E W S}$ : Depreciation of existing workcentre $o$

$D E P_{p}^{N W S}$ : Depreciation of new workcentre $p$ 
$D E P_{j}^{E N G}$ : Depreciation of equipment in engineering department $j$

$G A_{o, t}^{E W S}$ : General assets allocation cost to existing workcentre $o$ in period $t$

$G A_{p, t}^{N W S}$ : General assets allocation cost to new workcentre $p$ in period $t$

$G A_{j, t}^{E N G}:$ General assets allocation cost to department $j$ in period $t$

$c_{m}^{M O D}:$ purchase cost of functional module $m$

$c_{p}^{M C}:$ purchase cost of new workcentre $p$

The decision variables are:

$a_{j, t}$ : Hourly rate for engineering department $j$ in production period $t$

$b_{o, t}:$ Hourly rate for workcentre $o$ in production period $t$

$b_{p, t}^{N E W}:$ Hourly rate for new workcentre $p$ in production period $t$

$B u y_{o, m t}^{M O D}=\left\{\begin{array}{l}1, \text { if module } m \text { is bought for workcentre } o \text { in production period } t \\ 0, \text { otherwise }\end{array}\right.$

$B u y_{p, t}^{M C}=\left\{\begin{array}{l}1, \text { if new workcentre } p \text { is bought in production period } t \\ 0, \text { otherwise }\end{array}\right.$

$M O D_{o, m, t}=\left\{\begin{array}{l}1, \text { if module } m \text { is required in workcentre } o \text { in production period } t \\ 0, \text { otherwise }\end{array}\right.$

$M C_{p, t}=\left\{\begin{array}{l}1, \text { if workcentre } o \text { is required in production period } t \\ 0, \text { otherwise }\end{array}\right.$

$x_{i, t}=\left\{\begin{array}{l}1, \text { if job } i \text { is chosen in production period } t \\ 0, \text { otherwise }\end{array}\right.$

The objective function is concerned with maximizing the profit in which it is required to minimize the difference between total cost and total selling price. Several assumptions are considered while formulating the objective function. For example, raw materials are purchased for each job and therefore, no carrying or holding cost is considered in this paper. The objective function is written as shown in Equation (2).

The mathematical model only considers mechanical and electrical engineering as well as manufacturing as direct labour cost. Factory overhead and indirect costs are allocated to the direct hourly rates. In Equation (2), the first term is the raw material/commercial items cost. The second term is the total engineering cost. In ABC method terms, second term is the product level. The third term is the total production cost. In ABC method terms, the third term is the unit level. The fourth term is the total setup cost. In ABC method terms, the fourth term is the batch level. The fifth and sixth terms are the buying costs of functional modules and adding new workcentres, respectively. Finally, the seventh term is the selling cost. In the 
fourth term, the symbol $\varepsilon$ is a small number (e.g. 0.0005) to prevent an infinite value for the fourth term in case where $Q_{i, t}$ is equal to zero.

\section{Min Z}

$$
\begin{aligned}
& \sum_{i=1}^{I} \sum_{t=1}^{T} d_{i, t} Q_{i, t} x_{i, t}+\sum_{i=1}^{I} \sum_{j=1}^{J} \sum_{t=1}^{T} h_{i, j} a_{j, t} x_{i, t} \\
+ & \sum_{i=1}^{I} \sum_{o=1}^{O} \sum_{t=1}^{T} Q_{i, t} g_{i, o} b_{o, t} x_{i, t}+\sum_{i=1}^{I} \sum_{o=1}^{O} \sum_{t=1}^{T} \frac{\left(k_{i, o} b_{o, t} x_{i, t}\right)}{Q_{i, t}+\varepsilon} \\
+ & \sum_{o=1}^{O} \sum_{m=1}^{M} \sum_{t=1}^{T} c_{m}^{M O D} B u y_{o, m t}^{M O D}+\sum_{p=1}^{P} \sum_{t=1}^{T} c_{p}^{M C} B u y_{p, t}^{M C} \\
& -\sum_{i=1}^{I} \sum_{t=1}^{T} S_{i, t} Q_{i, t} x_{i, t}
\end{aligned}
$$

The constraints for the proposed model are:

$$
\begin{aligned}
& a_{j, t}=a_{0}+\frac{G A_{j, t}^{E N G}+D E P_{j}^{E N G}}{\sum_{i=1}^{I} x_{i, t_{0}} h_{i, j}}, \forall j=1,2 . . J, t=1,2 . . T, t_{0}=t-1 \\
& \begin{array}{ll}
b_{p, t}^{N E W}=b_{0}^{N E W}+\frac{G A_{p, t}^{N W S}+D E P_{p}^{N W S}}{\sum_{i=1}^{I} x_{i, t_{0}} Q_{i, t_{0}} g_{i, p}^{N E W}}, & \forall p=1,2 . . P, t=1,2 . . T, t_{0}=t-1 \\
b_{o, t}=b_{0}+\frac{G A_{o, t}^{E W S}+D E P_{o}^{E W S}}{\sum_{i=1}^{I} x_{i, t_{0}} Q_{i, t_{0}}\left(g_{i, o}+\sum_{m=1}^{M} f_{m, i, o} M O D_{o, m, t_{0}}\right)} & \forall o=1,2 . . O, t=1,2 . . T, t_{0}=t-1
\end{array}
\end{aligned}
$$

$$
\sum_{i=1}^{I}\left(g_{i, p}^{N E W} Q_{i, t} x_{i, t}+k_{i, p}^{N E W} x_{i, t}\right) \leq C_{p, t}^{M N E W}, \forall p=1,2 . . P, t=1,2 . . T
$$

$$
\begin{aligned}
\sum_{i=1}^{I}\left(g_{i, o} Q_{i, t} x_{i, t}+\sum_{m=1}^{M} f_{m, i, o} M O D_{o, m, t} Q_{i, t} x_{i, t}+k_{i, o} x_{i, t}\right) & \leq C_{t, o}^{M} \\
\forall o & =1,2 . . O, t=1,2 . . T
\end{aligned}
$$

$\sum_{i=1}^{I} h_{i, j} x_{i, t} \leq C_{j, t}^{E}, \forall j=1,2 . . J, t=1,2 . . T$

$$
\begin{aligned}
M O D_{o, m, t} \leq \sum_{i=1}^{I} f_{m, i, o} x_{i, t}\left(1-e_{i, o}\right) \leq M O D_{o, m, t} B i g M, & \\
& \forall o=1,2 . . O, t=1,2 . . T, m=1,2 . . M
\end{aligned}
$$




$$
\begin{aligned}
& B u y_{o, m, t}^{M O D} B i g M-B i g M+1 \leq M O D_{o, m, t}-M O D_{o, m, t_{0}} \\
& \leq(1-\varepsilon)\left(1-B u y_{o, m, t}^{M O D}\right)+B u y_{o, m, t}^{M O D}, \\
& \forall o=1,2 . . O, m=1,2 . . M, t=1,2 . . T, t 0=t-1 \\
& B u y_{p, t}^{M C} B i g M-B i g M+1 \leq M C_{p, t}-M C_{p, t_{0}} \leq(1-\varepsilon)\left(1-B u y_{p, t}^{M C}\right)+B u y_{p, t}^{M C}, \\
& \forall p=1,2 . . P, t=1,2 . . T, t 0=t-1 \\
& \sum_{i=1}^{I} x_{i, t} \geq 1, \forall i=1,2 . . I, t=1,2 . . T
\end{aligned}
$$

Equation (3) is an equality constraint. It is used to represent the bi-directional between the hourly rates for department $j$ in production period $t$ and the hours assigned to department $j$ in the previous production period $t_{0}$. Similarly, Equation (4) represents the bi-directional relationship between hourly rates for new workcentre $p$ in production period $t$ and the hours assigned to new workcentre $p$ in the previous production period $t_{0}$. Equation (5) represents the bi-directional relationship between hourly rates for workcentre $o$ in production period $t$ and the hours assigned to workcentre $o$ in the previous production period $t_{0}$.

Equation (6) represents the capacity of the new workcentre $p$ in production period $t$ in hours. Equation (7) represents the capacity of the existing workcentre $o$ in production period $t$. The left hand side of Equation (7) is composed of three terms. The first term $\left(g_{i, o} Q_{i, t} x_{i, t}\right)$ represents the total hours required for job $i$ on existing workcentre $o$. The second term

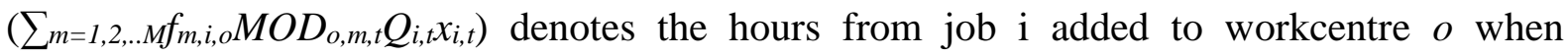
adding additional functional module $m$ in production period $t$. The third term $\left(k_{i, o} x_{i, t}\right)$ is the setup hours required by job $i$ on workcentre $o$.

Equation (8) is the available capacity in department $\mathrm{j}$ during production period $\mathrm{t}$. Equation (9) represents the condition in which a functional module $m$ is required by workcentre $o$ in production period $t$. If functional module $m$ when added to workcentre $o$ can machine job $i$ (i.e. $f_{m, i, o}>0$ ) but workcentre $o$ without the additional functional module $m$ cannot machine job i (i.e.l- $\left.e_{i}, o=1\right)$, therefore, functional module $m$ is required by workcentre $o$ (i.e. $M O D_{m, o, t}=1$ ). Equation (10) represents the condition in which purchasing of additional functional module $m$ in production period $t$ for workcentre $o$ takes place $\left(\right.$ Buymod $\left._{o, m, t}\right)$. If in two subsequent periods $t$ and $t+1$, functional module $m$ is required by workcentre $o$ (i.e. $M O D_{o, m, t+1}=1$ and $\left.M O D_{o, m, t}=1\right)$, then there is no purchasing of the additional functional module taking place in production period $t+1$ (i.e. Buymod $_{o, m, t+1}=0$ ). However, if functional module $m$ is not required by workcentre $o$ in production period $t$ (i.e. $M O D_{o, m, t}=0$ ), but functional module $m$ is required by workcentre $o$ in production period $t+1$ (i.e. $M O D_{o, m, t+l}=1$ ), therefore, purchasing a new module is required in production period $t+1$ (i.e. Buymod $_{o, m, t+1}=1$ ).d Equation (11) represents the condition in which a new workcentre $p$ is to be purchased in production period $t$. This constraint can be illustrated similar to constraint Equation (9).

Finally, Equation (12) represents the condition in which at least one job is selected in each production period. It is evident that several non-linear terms exist in the constraints equations. For example, the second term on the left hand side of Equation (7)

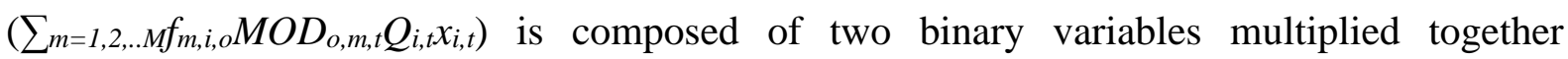
$\left(M O D_{o, m, t}\right.$ and $\left.x_{i, t}\right)$ which requires obtaining such variables in their linear form in order to use 
MILP. Reader may refer to [28] for further readings on linearization techniques.

\section{6- Industrial Case Study}

The case study discussed in this paper is adopted from a local machine shop and is part of a multinational machinery builder company situated in Europe. The company shop area is around 5,000 $\mathrm{m} 2$ with various departments such welding, fabrication, machining and assembly. The inputs to the model are shown in Table 1 to Table 8 . The name of each workcentre is described as a symbol WS as actual names of workcentres were not allowed to be disclosed. As per Equation (1), the hourly rate for a certain workcentre at a specific production period is calculated based on the assigned hours for the workcentre in the previous period. Hence, the hourly rate for workcentres and departments for production period 1 are considered constant and the values are shown in Table 1 and Table 2. The blended costs for existing workcentres, new workcentres and engineering department $b_{0}, b_{0}{ }^{N E W}$ and $a_{0}$, respectively, are taken as $\$ 60 / \mathrm{hr}$. The number production periods considered are six production periods in which each period is considered a quarter of a year.

Table 1. General assets allocated cost to each existing workcentre and depreciation cost/yr for each existing workcentre in (\$)

\begin{tabular}{|ccccl|}
\hline index & $\begin{array}{c}\text { Hourly } \\
\text { rate at } \mathrm{t}=1\end{array}$ & $\begin{array}{c}\text { Existing } \\
\text { Workcentre }\end{array}$ & $\begin{array}{c}\text { General assets } \\
\text { allocated Cost } \\
(\$)\end{array}$ & $\begin{array}{c}\text { Depreciation/yr } \\
(\$)\end{array}$ \\
\hline $\mathrm{o}=1$ & $\$ 62$ & WS-01 & $\$ 20,141.36$ & $\$-$ \\
$\mathrm{o}=2$ & $\$ 62$ & WS-02 & $\$ 59,057.32$ & $\$-$ \\
$\mathrm{o}=3$ & $\$ 65$ & WS-03 & $\$ 59,057.32$ & $\$-$ \\
$\mathrm{o}=4$ & $\$ 100$ & WS-04 & $\$ 14,061.27$ & $\$ 29,180.00$ \\
$\mathrm{o}=5$ & $\$ 65$ & WS-05 & $\$ 15,186.17$ & $\$ 110,020.00$ \\
$\mathrm{o}=6$ & $\$ 85$ & WS-06 & $\$ 14,061.27$ & $\$ 29,180.00$ \\
$\mathrm{o}=7$ & $\$ 85$ & WS-07 & $\$ 8,436.76$ & $\$ 3,440.00$ \\
$\mathrm{o}=8$ & $\$ 125$ & WS-08 & $\$ 7,030.63$ & $\$ 73,630.00$ \\
$\mathrm{o}=9$ & $\$ 85$ & WS-09 & $\$ 15,186.17$ & $\$ 187,950.00$ \\
$\mathrm{o}=10$ & $\$ 62$ & WS-10 & $\$ 20,141.36$ & $\$ 2,710.00$ \\
$\mathrm{o}=11$ & $\$ 62$ & WS-11 & $\$ 59,057.32$ & $\$-$ \\
$\mathrm{o}=12$ & $\$ 62$ & WS-12 & $\$ 59,057.32$ & $\$-$ \\
$\mathrm{o}=13$ & $\$ 62$ & WS-13 & $\$ 59,057.32$ & $\$-$ \\
$\mathrm{o}=14$ & $\$ 62$ & WS-14 & $\$ 59,057.32$ & $\$-$ \\
$\mathrm{o}=15$ & $\$ 62$ & WS-15 & $\$ 59,057.32$ & $\$-$ \\
$\mathrm{o}=16$ & $\$ 62$ & WS-16 & $\$ 20,141.36$ & $\$-$ \\
$\mathrm{o}=17$ & $\$ 62$ & WS-17 & $\$ 20,141.36$ & $\$-$ \\
$\mathrm{o}=18$ & $\$ 62$ & WS-18 & $\$ 20,141.36$ & $\$-$ \\
\hline
\end{tabular}

Table 2. General assets allocated cost to each new workcentre and depreciation cost/yr for each new workcentre in $(\$)$

\begin{tabular}{|ccccc|}
\hline $\begin{array}{c}\text { Workcentre } \\
\text { Index }\end{array}$ & $\begin{array}{c}\text { Hourly } \\
\text { rate at } \mathrm{t}=1\end{array}$ & Workcentre & $\begin{array}{c}\text { General assets } \\
\text { allocated Cost } \\
(\$)\end{array}$ & $\begin{array}{c}\text { Depreciation/yr } \\
(\$)\end{array}$ \\
\hline $\mathrm{p}=1$ & $\$ 62$ & WS-01 & $\$ 20,141.36$ & $\$ 29,180$ \\
$\mathrm{p}=2$ & $\$ 62$ & WS-02 & $\$ 59,057.32$ & $\$ 29,180$ \\
$\mathrm{p}=3$ & $\$ 65$ & WS-03 & $\$ 59,057.32$ & $\$ 3,000$ \\
\hline
\end{tabular}


Table 3. Hours required by engineering departments 1 and 2 to complete job $i$

\begin{tabular}{|c|c|c|c|c|c|c|c|c|c|c|c|}
\hline & & \multicolumn{10}{|c|}{ Job } \\
\hline & & $\mathrm{i}=1$ & $\mathrm{i}=2$ & $\mathrm{i}=3$ & $\mathrm{i}=4$ & $i=5$ & $i=6$ & $\mathrm{i}=7$ & $i=8$ & $i=9$ & $\mathrm{i}=10$ \\
\hline \multirow{2}{*}{ Dept. } & $\mathrm{j}=1$ & 610 & 690 & 770 & 920 & 560 & 520 & 170 & 760 & 510 & 110 \\
\hline & $\mathrm{j}=2$ & 500 & 300 & 810 & 180 & 320 & 280 & 840 & 960 & 390 & 820 \\
\hline
\end{tabular}

Table 4. Available jobs required machining hours on each new workcentre, selling price in \$ and raw material cost in $\$$

\begin{tabular}{|lllccc|}
\hline & & & & & \\
Job & Selling price & \multicolumn{2}{c|}{ Raw material } & new workcentres available \\
index & in $(\$)$ & cost in $(\$)$ & $\mathrm{p}=1$ & $\mathrm{p}=2$ & $\mathrm{p}=3$ \\
$\mathrm{i}=1$ & $\$ 1,347,660$ & $\$ 36,866$ & 400 & 1755 & 785 \\
$\mathrm{i}=2$ & $\$ 1,254,225$ & $\$ 97,531$ & 657.5 & 1040 & 592.5 \\
$\mathrm{i}=3$ & $\$ 1,954,685$ & $\$ 21,615$ & 400 & 100 & 500 \\
$\mathrm{i}=4$ & $\$ 1,373,780$ & $\$ 99,247$ & 400 & 890 & 500 \\
$\mathrm{i}=5$ & $\$ 1,303,530$ & $\$ 96,111$ & 400 & 297.5 & 250 \\
$\mathrm{i}=6$ & $\$ 471,850$ & $\$ 35,654$ & 600 & 935 & 1520 \\
$\mathrm{i}=7$ & $\$ 1,961,505$ & $\$ 32,793$ & 400 & 200 & 5539 \\
$\mathrm{i}=8$ & $\$ 717,165$ & $\$ 69,500$ & 147.5 & 330 & 55 \\
$\mathrm{i}=9$ & $\$ 645,540$ & $\$ 99,464$ & 195 & 340 & 50 \\
$\mathrm{i}=10$ & $\$ 1,555,845$ & $\$ 31,337$ & 135 & 370 & 15 \\
\hline
\end{tabular}

Table 5. Sample machining and setup hours (between brackets) required for job i on existing workcentre o

\begin{tabular}{|lllrlllll|}
\hline $\begin{array}{r}\text { Job } \\
\text { index }\end{array}$ & \multicolumn{7}{c}{ Available workcentre } \\
\hline $\mathrm{i}=1$ & $82.048(2)$ & $1755(1)$ & $1240(1)$ & $670(1)$ & $80(1)$ & $267.5(1)$ & $50(1)$ \\
$\mathrm{i}=2$ & $657.5(2)$ & $1040(2)$ & $0(0)$ & $760.5(2)$ & $756(2)$ & $677.5(1)$ & $0(0)$ \\
$\mathrm{i}=3$ & $60(2)$ & $100(2)$ & $100(2)$ & $150(1)$ & $50(2)$ & $0(0)$ & $200(2)$ \\
$\mathrm{i}=4$ & $145(1)$ & $890(1)$ & $200(1)$ & $150(1)$ & $300(1)$ & $105(1)$ & $40(2)$ \\
$\mathrm{i}=5$ & $115(2)$ & $297.5(2)$ & $200(1)$ & $192.5(2)$ & $300(2)$ & $100(2)$ & $110(2)$ \\
$\mathrm{i}=6$ & $30(1)$ & $935(2)$ & $90(1)$ & $1107.5(2)$ & $82.5(1)$ & $80(2)$ & $880(1)$ \\
$\mathrm{i}=7$ & $0(0)$ & $0(0)$ & $0(0)$ & $0(0)$ & $0(0)$ & $0(0)$ & $0(0)$ \\
$\mathrm{i}=8$ & $147.5(1)$ & $330(2)$ & $185(2)$ & $80(1)$ & $142.5(1)$ & $70(1)$ & $50(1)$ \\
$\mathrm{i}=9$ & $195(2)$ & $340(2)$ & $230(2)$ & $202.5(1)$ & $167.5(1)$ & $75(1)$ & $10(1)$ \\
$\mathrm{i}=10$ & $135(2)$ & $370(1)$ & $250(1)$ & $100(2)$ & $167.5(1)$ & $70(1)$ & $20(2)$ \\
\hline
\end{tabular}


Table 6. Available capacity for existing workcentres and engineering departments in production periods 1 up to 6 in hours

\begin{tabular}{|lcccccccccc|}
\hline & \multicolumn{1}{c|}{ Existing workcentres } & & & \\
& $1,3,12$ & & & & & & & Departments \\
& 13,14 & & 4,6 & & & & 11,17 & & \\
& 15,16 & 2 & 9,10 & 5 & 7 & 8 & 18 & 1 & 2 \\
\hline $\mathrm{t}=1$ to & & & & & & & & & \\
$\mathrm{t}=6$ & 9600 & 7680 & 4800 & 2880 & 2160 & 3840 & 1920 & 2000 & 2000 \\
\hline
\end{tabular}

The general assets allocated to workcentres and activities are shown in Table 1 and Table 2. Though the general assets allocated to workcentre/activities must be calculated as per illustration in section 3 , it is taken directly from company's records as constant to avoid further linearization of terms in the model.

Table 7. Available capacity for new workcentres available for purchasing in production periods 1 up to 6 in hours

\begin{tabular}{|lccc|}
\hline $\begin{array}{l}\text { Production } \\
\text { periods }\end{array}$ & \multicolumn{3}{c|}{ New workcentres } \\
& $p=1$ & $p=2$ & $p=3$ \\
\hline$t=1$ to $t=6$ & 9600 & 7680 & 9600 \\
\hline
\end{tabular}

Table 8. Machining hours required by each available job when functional module $m=1$ is added to existing workcentres

\begin{tabular}{|rcccccc|}
\hline Job & \multicolumn{7}{c|}{ Available workcentres } \\
index & $o=4$ & $o=5$ & $o=6$ & $o=7$ & $o=8$ & $o=9$ \\
\hline$i=1$ & 795 & 40 & 600 & 0 & 0 & 760 \\
$i=2$ & 1267 & 1900 & 3365 & 895 & 0 & 600 \\
$i=3$ & 0 & 0 & 70 & 300 & 0 & 0 \\
$i=4$ & 200 & 105 & 0 & 0 & 0 & 1850 \\
$i=5$ & 100 & 100 & 0 & 0 & 0 & 1500 \\
$i=6$ & 140 & 505 & 1670 & 472.5 & 0 & 720 \\
$i=7$ & 0 & 0 & 0 & 0 & 0 & 0 \\
$i=8$ & 680 & 750 & 50 & 100 & 150 & 400 \\
$i=9$ & 40 & 750 & 250 & 0 & 180 & 400 \\
$i=10$ & 110 & 750 & 250 & 200 & 190 & 400 \\
\hline
\end{tabular}

\section{7- Results and Discussions}

The objective function is concerned with maximizing the profit in which it is required to minimize the difference between total cost and total selling price. Several assumptions are considered while formulating the objective function. The Mixed Integer Linear Programming (MILP) model is written using AMPL (http://ampl.com/) and solved using Gurobi in Neos [29-31].

The results from the model are presented in Fig. 4 to Fig. 8 and Table 9. Fig. 4 shows the hourly rates for the engineering departments during the 6 production periods. The first period is taken as the blended cost as illustrated in Equation (1). The hourly rate increases to the maximum at period 5 for the two departments. Since each hourly rate is calculated based on the total hours in the previous period, therefore, the hourly rates for period 5 are calculated 
based on the hours from period 4. From Table 9 and Table 3, the total engineering hours for departments 1 and 2 are 1640 and 1500 hours, respectively compared to 1970 and 1940 hours for periods 1, 2, 3 and 5 for departments 1 and 2, respectively. Therefore, in order to reduce the hourly rate further, the manufacturing firm is required to accept more jobs from customers in order to reduce the hourly rates.

Table 9. Jobs accepted in each production period

\begin{tabular}{|rrrrrrrrrrrr|}
\hline & & $\mathrm{i}=1$ & $\mathrm{i}=2$ & $\mathrm{i}=3$ & $\mathrm{i}=4$ & $\mathrm{i}=5$ & $\mathrm{i}=6$ & $\mathrm{i}=7$ & $\mathrm{i}=8$ & $\mathrm{i}=9$ & $\mathrm{i}=10$ \\
\hline \multirow{4}{*}{ Periods } & $\mathrm{t}=1$ & 1 & 1 & 0 & 0 & 1 & 0 & 0 & 0 & 0 & 1 \\
& $\mathrm{t}=2$ & 1 & 1 & 0 & 0 & 1 & 0 & 0 & 0 & 0 & 1 \\
& $\mathrm{t}=3$ & 1 & 1 & 0 & 0 & 1 & 0 & 0 & 0 & 0 & 1 \\
& $\mathrm{t}=4$ & 1 & 0 & 0 & 1 & 0 & 0 & 0 & 0 & 0 & 1 \\
& $\mathrm{t}=5$ & 1 & 1 & 0 & 0 & 1 & 0 & 0 & 0 & 0 & 1 \\
$\mathrm{t}=6$ & 0 & 0 & 1 & 1 & 0 & 0 & 1 & 0 & 0 & 0 \\
\hline
\end{tabular}

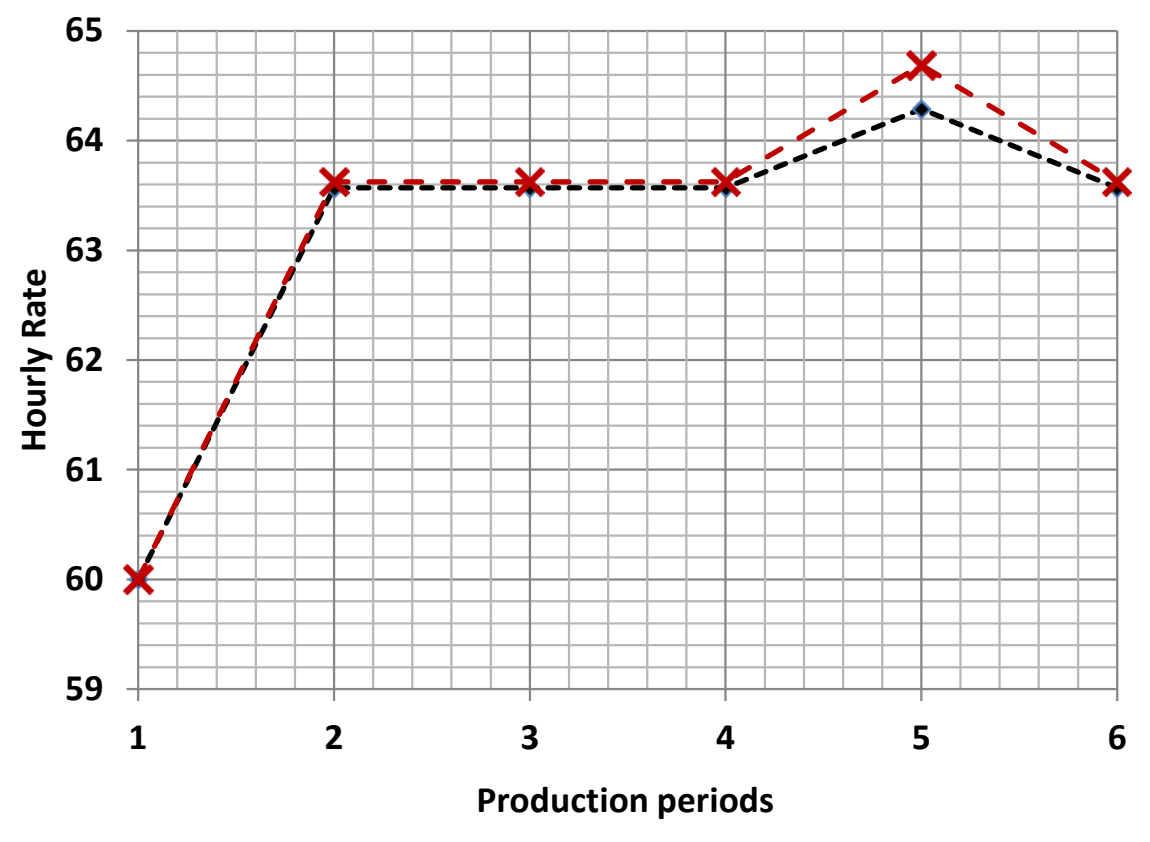

--- Engg. Dept. 1 - - Engg. Dept. 2

Fig. 4. Hourly rates for engineering departments 1 and 2 during the 6 production periods

Fig. 7 presents the results of the machining hourly rates variation with the different production periods. The machining hourly rates peaks at production period 5 due to the reduced assigned total machining hours in production period 4 which is equal to 5250 hours compared to 6697.5 hours for production periods 1, 2, 3 and 5 and 8929 hours for production period 6. Fig. 8 presents the reconfiguration level decision on the machine and system level. In production period 1, the mathematical model suggests purchasing three new workcentres

Fig. 5 and Fig. 6 shows the hourly rates for workcentres WS-01 to WS-09 and WS-10 to WS-18, respectively. From Table 9 and Table 5, the total machining hours in production period 4 sums up to 11249.55 hours compared to 18178.55 hours for production periods 1,2 , 
3 and 5. Therefore, the hourly rates for production period 5 peaks to the maximum value as per Equation (1). For hourly rates of WS-04 and WS-07 in Fig. 5, the hourly rates are decreased in production period 2 since the total machining hours in production period 1 is at its maximum of $181,718.55$ hours.

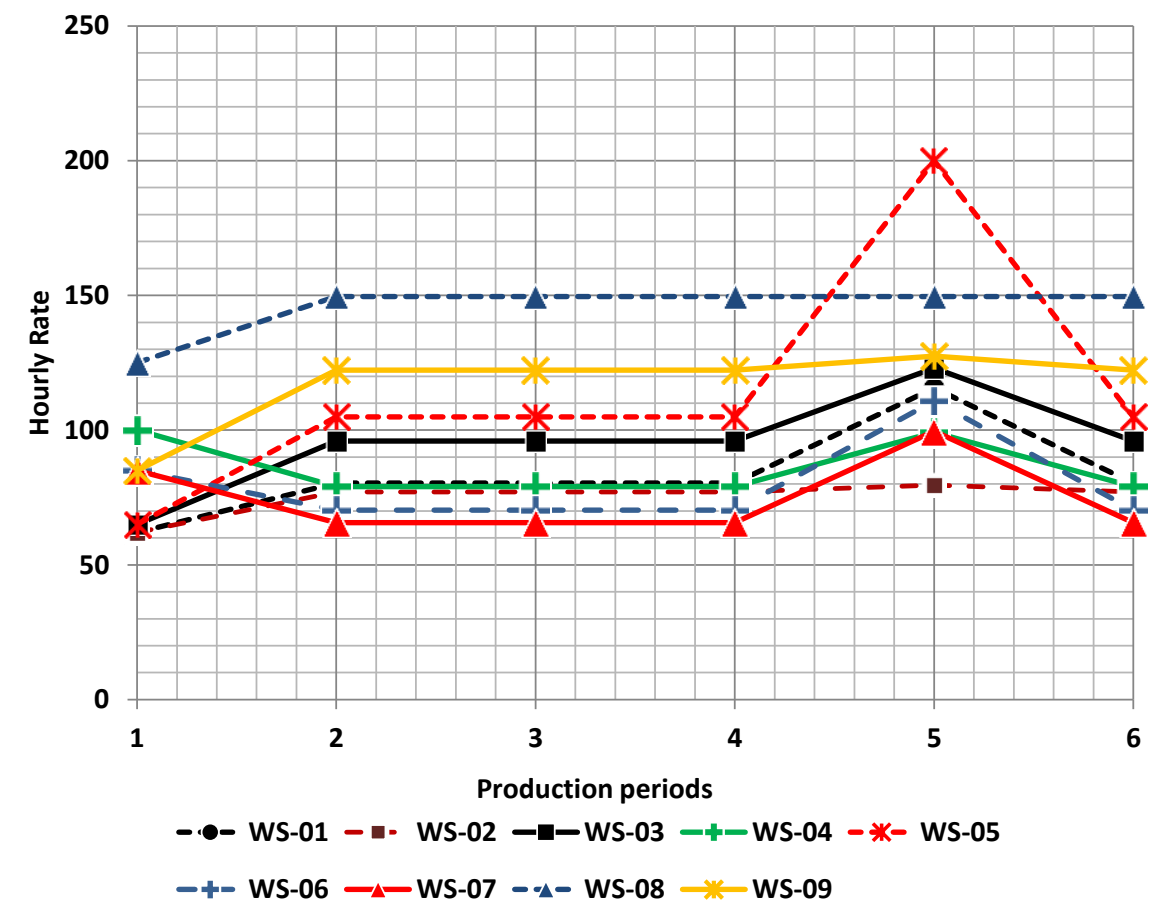

Fig. 5. Hourly rates for existing workcentres WS-01 to WS-09 in the 6 production periods

The reason for this decision is to increase the available machining capacity within the facility, and hence, more jobs can be accepted. The model also suggests adding functional module 1 to the existing workcentres WS-04, WS-05, WS-06, WS-07 and WS-09. The reason for this decision is to extend the functionality of the existing workcentres in order to accept jobs containing new features that cannot be machined by the existing system's capability.

To this extent, the more jobs being accepted, the more reduction in job cost will be encountered as a result of reducing the hourly machining rates. It is worth noting that reducing hourly rates and hence, job cost, will put the manufacturing company at a competitive edge among its rivals due to following the cost leadership business strategy and accordingly, higher probability to get more jobs from customers. 


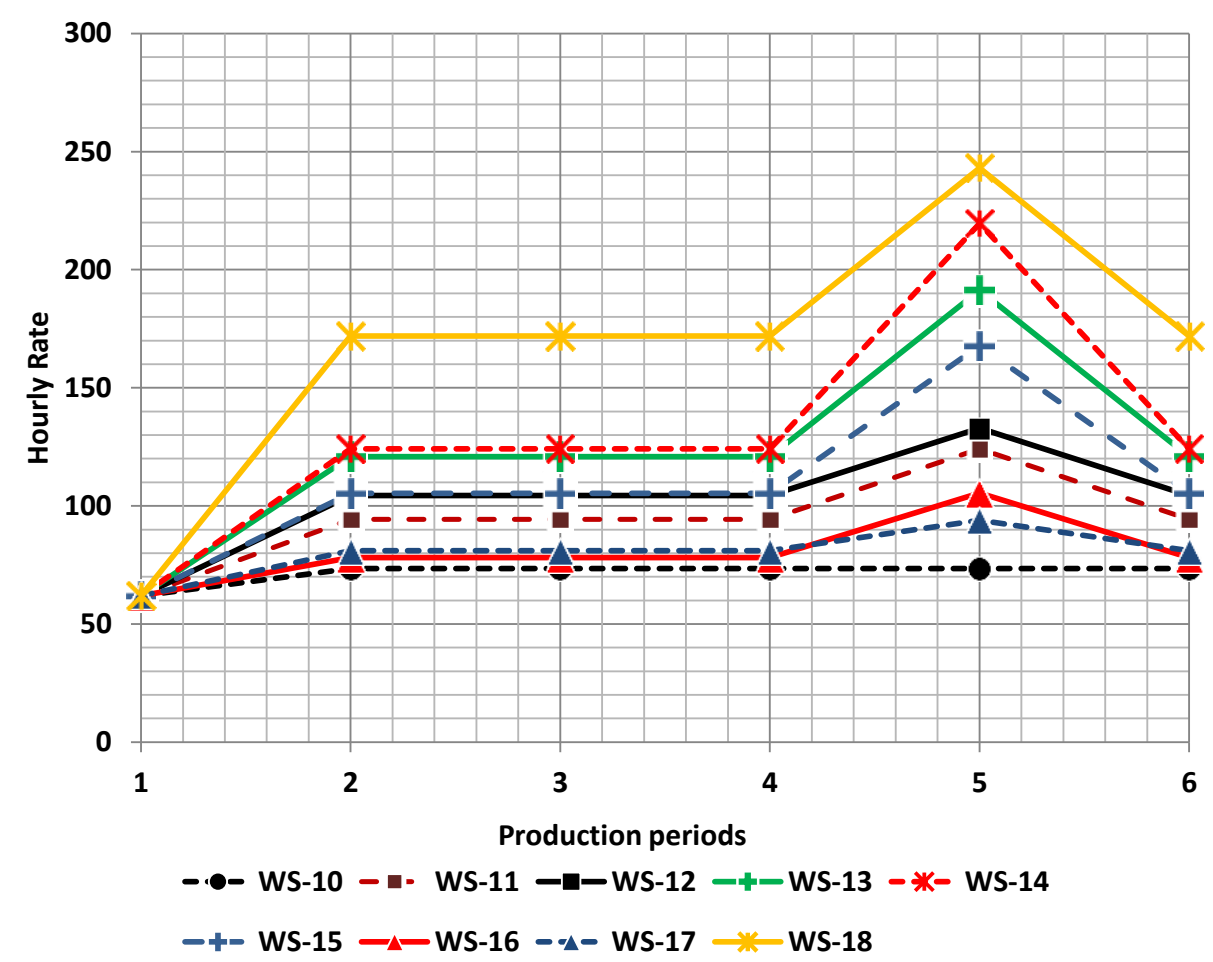

Fig. 6. Hourly rates for existing workcentres WS-10 to WS-18 in the 6 production periods

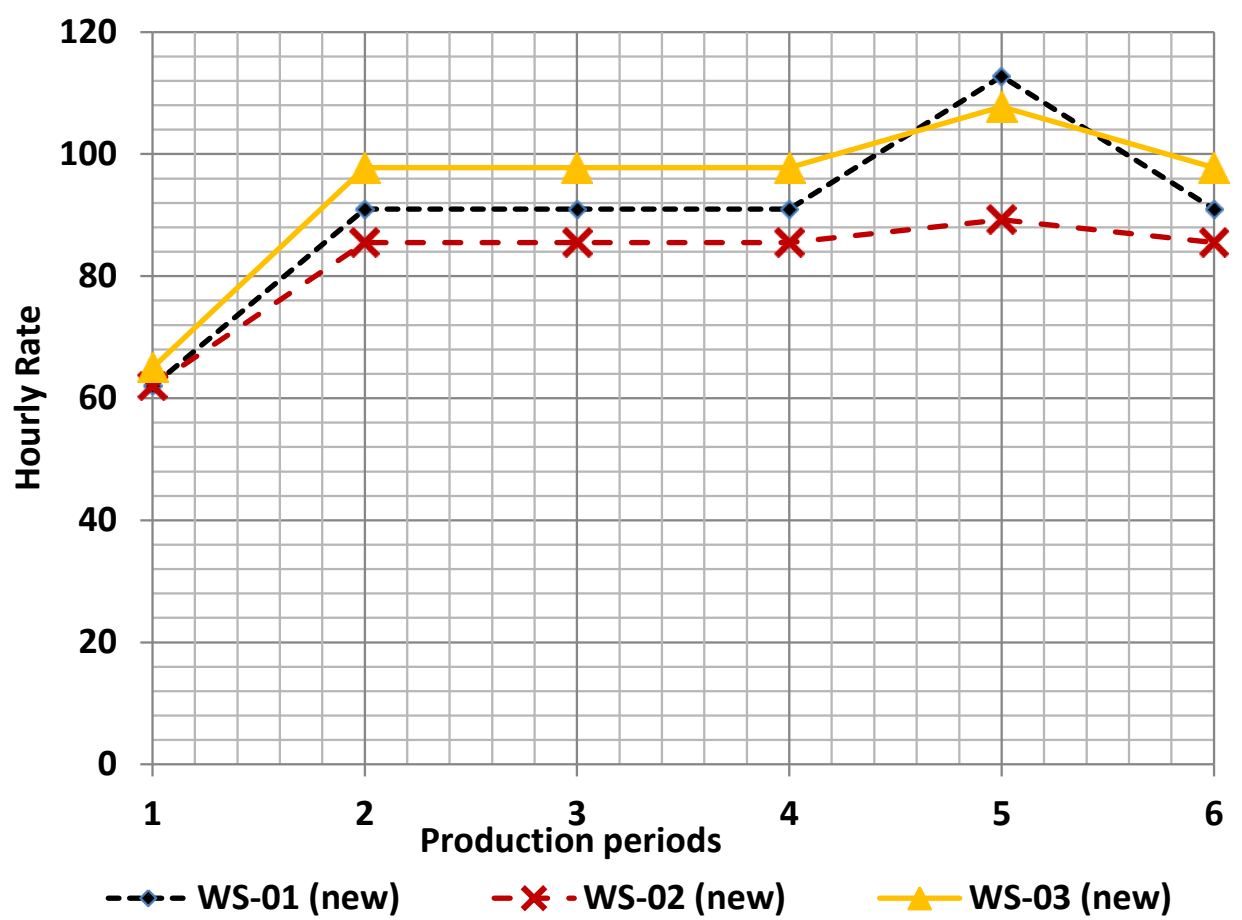

Fig. 7. Hourly rates for the new workcentres in the 6 production periods 


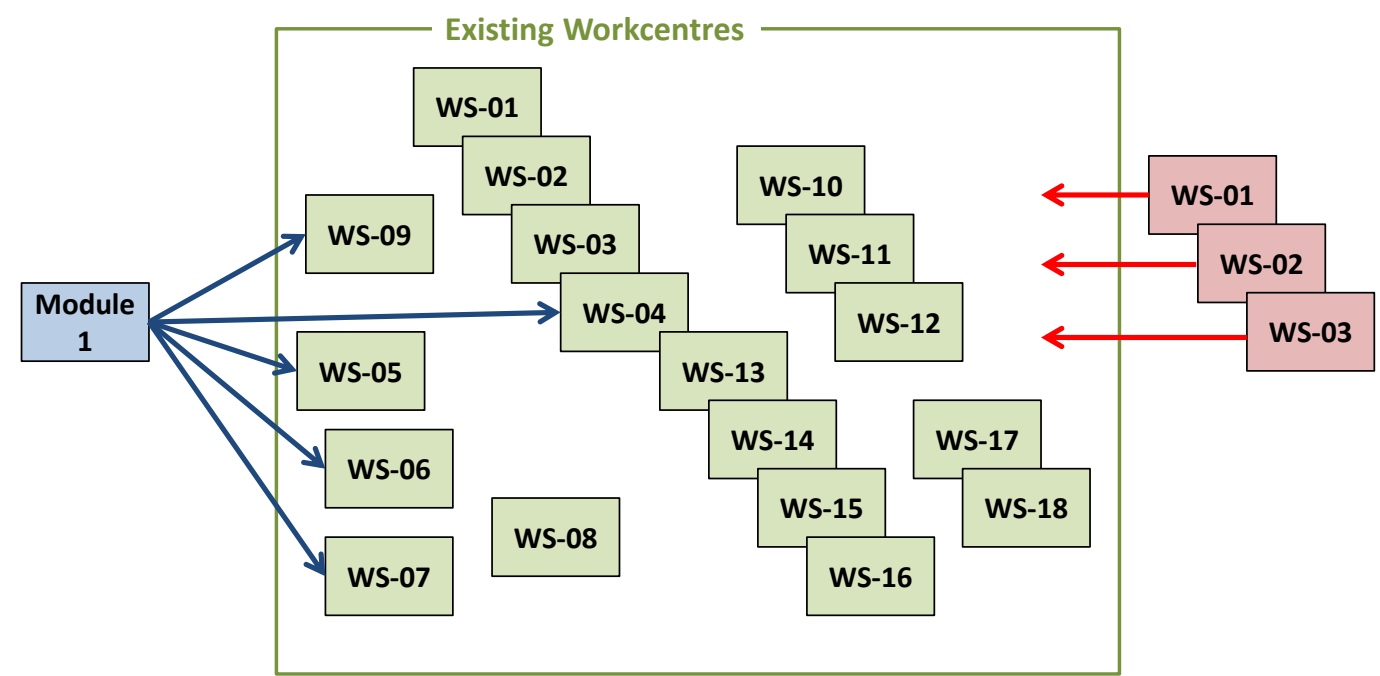

Fig. 8. Workcentres/modules reconfiguration decision

\section{8- Conclusion}

This paper introduces a novel mathematical model to minimize the total cost incurred in a Reconfigurable Manufacturing System environment across production periods. The cost objects, in this case, refer to the jobs being processed within the manufacturer's floor. The objective function developed is to minimize the total manufacturing cost and increase profit through a proposed $\mathrm{ABC}$ model. In addition, the mathematical model takes into consideration the bi-directional relationship between the number of hours assigned to workcentres/departments and the hourly rates. The main outputs from the mathematical model are the newly calculated hourly rates for the different workcentres/departments, the jobs mix decision as well as functional modules and workcentres reconfiguration decisions. The proposed mathematical model is applied to a case study taken from a local heavy machinery builder machine shop.

The significance of this paper is not restricted to cost analysis, but also to provide managers in manufacturing facilities with the required decision-making tools to decide on orders to accept or refuse as well as investing in additional production equipment. In addition, this paper will assist manufacturing companies to achieve a competitive edge among rivals through reduction of hourly rates within their facility. Additional benefits and significance are (1) providing manufacturing companies a method to quantify the decisionmaking process for right-sizing their manufacturing space (2) ability to justify growing a scalable system using costing (not customer demand) (3) expanding market share and (4) reducing operational cost and allowing companies a numerical model to justify scaling the manufacturing system. 


\section{References}

[1] S. B. Hughes and K. A. Paulson Gjerde, "Do different cost systems make a difference?," Management Accounting Quarterly, vol. 5, p. 22, 2003.

[2] M. Geiszler, K. Baker, and J. Lippitt, "Variable Activity-Based Costing and Decision Making," Journal of Corporate Accounting \& Finance, vol. 28, pp. 45-52, 2017.

[3] C. R. Monroy, A. Nasiri, and M. Á. Peláez, "Activity Based Costing, Time-Driven Activity Based Costing and Lean Accounting: Differences among three accounting systems' approach to manufacturing," in Annals of Industrial Engineering 2012, ed: Springer, 2014, pp. 11-17.

[4] B. H. Maskell and F. A. Kennedy, "Why do we need lean accounting and how does it work?," Journal of Corporate Accounting \& Finance, vol. 18, pp. 59-73, 2007.

[5] S. M. Bragg. (2013). Throughput accounting : a guide to constraint management. Available: http://rbdigital.oneclickdigital.com

[6] R. Kee and C. Schmidt, "A comparative analysis of utilizing activity-based costing and the theory of constraints for making product-mix decisions," International journal of production economics, vol. 63, pp. 1-17, 2000.

[7] J. G. Fisher and K. Krumwiede, "Product costing systems: Finding the right approach," Journal of Corporate Accounting \& Finance, vol. 23, pp. 43-51, 2012.

[8] S. M. Datar and M. Rajan, "Horngren's Cost Accounting: A Managerial Emphasis," 2018.

[9] T. Lin, J.-W. Lee, and E. Bohez, "New integrated model to estimate the manufacturing cost and production system performance at the conceptual design stage of helicopter blade assembly," International journal of production research, vol. 50, pp. 7210-7228, 2012.

[10] M. Ramadan, H. Al-Maimani, and B. Noche, "RFID-enabled smart real-time manufacturing cost tracking system," The International Journal of Advanced Manufacturing Technology, vol. 89, pp. 969985, 2017.

[11] A. Myrelid and J. Olhager, "Hybrid manufacturing accounting in mixed process environments: A methodology and a case study," International Journal of Production Economics, vol. 210, pp. 137-144, 2019.

[12] T. V. Elsukova, "Lean accounting and throughput accounting: an integrated approach," Mediterranean Journal of Social Sciences, vol. 6, p. 83, 2015.

[13] N. Sajadfar and Y. Ma, "A hybrid cost estimation framework based on feature-oriented data mining approach," Advanced Engineering Informatics, vol. 29, pp. 633-647, 2015.

[14] L. Jiang, D. Walczyk, G. McIntyre, and W. K. Chan, "Cost modeling and optimization of a manufacturing system for mycelium-based biocomposite parts," Journal of Manufacturing Systems, vol. 41, pp. 8-20, 2016.

[15] O. Duran and P. S. L. P. Afonso, "An activity based costing decision model for life cycle economic assessment in spare parts logistic management," International Journal of Production Economics, p. 107499, 2019.

[16] A. Santana, P. Afonso, A. Zanin, and R. Wernke, "Costing models for capacity optimization in Industry 4.0: Trade-off between used capacity and operational efficiency," Procedia Manufacturing, vol. 13, pp. 1183-1190, 2017.

[17] W.-H. Tsai, P.-Y. Chu, and H.-L. Lee, "Green Activity-Based Costing Production Planning and Scenario Analysis for the Aluminum-Alloy Wheel Industry under Industry 4.0," Sustainability, vol. 11, p. 756, 2019.

[18] W.-H. Tsai and S.-Y. Lai, "Green production planning and control model with ABC under industry 4.0 for the paper industry," Sustainability, vol. 10, p. 2932, 2018.

[19] R. Cooper and R. S. Kaplan, "Measure costs right: make the right decisions," Harvard business review, vol. 66, pp. 96-103, 1988.

[20] R. Cooper and R. S. Kaplan, "How cost accounting distorts product costs," Strategic Finance, vol. 69, p. 20, 1988.

[21] Y. Yin, K. E. Stecke, and D. Li, "The evolution of production systems from Industry 2.0 through Industry 4.0," International Journal of Production Research, vol. 56, pp. 848-861, 2018.

[22] Y. Koren, "Reconfigurable Manufacturing System," in CIRP Encyclopedia of Production Engineering, ed: Springer, 2014, pp. 1035-1039.

[23] H. A. ElMaraghy, "Flexible and reconfigurable manufacturing systems paradigms," International journal of flexible manufacturing systems, vol. 17, pp. 261-276, 2005.

[24] M. G. Mehrabi, A. G. Ulsoy, and Y. Koren, "Reconfigurable manufacturing systems: Key to future manufacturing," Journal of Intelligent manufacturing, vol. 11, pp. 403-419, 2000. 
[25] T. Tolio, Design of flexible production systems: Springer, 2008.

[26] A. Aderoba, "A generalised cost-estimation model for job shops," International Journal of Production Economics, vol. 53, pp. 257-263, 1997.

[27] B. Esmaeilian, S. Behdad, and B. Wang, "The evolution and future of manufacturing: A review," Journal of Manufacturing Systems, vol. 39, pp. 79-100, 2016.

[28] FICO, "MIP Formulations and Linearization: A Quick Reference," Fair Isaac Corporation, pp. 1-19, 2009.

[29] J. Czyzyk, M. P. Mesnier, and J. J. Moré, "The NEOS server," IEEE Computational Science and Engineering, vol. 5, pp. 68-75, 1998.

[30] E. D. Dolan, "NEOS Server 4.0 administrative guide," arXiv preprint cs/0107034, 2001.

[31] W. Gropp and J. Moré, "Optimization Environments and the NEOS Server. Approximation Theory and Optimization, MD Buhmann and A. Iserles, eds," ed: Cambridge University Press, 1997. 